\title{
Build Local Animation Professional Brand Competitiveness in Industrial Segmentation
}

\author{
Zhu Zhou ${ }^{1}$ \\ Art and Media College \\ Xi'an Technological University \\ Xi'an, China \\ 313494854@qq.com
}

\author{
Yujuan Wang ${ }^{2}$ \\ Apparel \& Art Design College \\ Xi'an Polytechnic University \\ Xi'an, China \\ 835852935@qq.com
}

\begin{abstract}
The mismatching of referenced established colleges training modes and existing education resources resulted in local colleges' animation majors lacking of competitiveness, and the poor graduates employment situation is exactly the reflection. In hence, if they tend to improve their competitiveness under the increasingly fierce competition in this industry, they must find suitable education target and means through industrial segmentation, and set up different professional brands from those established colleges and universities.
\end{abstract}

\section{Keywords-animation; professional education; brand; competitiveness}

The boom of cultural industry provides a broad space for the talent demand to the development of animation industry, which in performance is widely set up cartoon animation majors in colleges all over the country, while the sustained low employment rate still warning professional survival crisis. Theoretically, the existing professional talents can provide with relatively abundant human resources to animation industry, but the fact is that the lax talent training quality control and single professional structure making the annual output of colleges "talent" either cannot meet the needs of industry or they can't find the ideal career during the competition with similar established colleges students. It is caused by outdated conditions and fuzzy even unreasonable positioning of local colleges. In hence, during the subsequent education market competition, on the premise of teaching quality, strengthening its own hardware and software from the concept of "big animation", reasonable positioning characteristics will be the basis of local colleges animation majors to set up brand, participate in market competition, long-term survival and development.

\section{SURVIVAL OF THE FITTEST OF THE PROFESSIONAL EDUCATION BASED ON MARKET EVOLUTION}

"We did to adjust the admission number of animation major, employment situation maybe some of the reasons, others concerns with development strategy adjustment", "We are about to reduce the recruitment of students on animation but the reducing indicators will be used on digital media

This is the periodic achievement of the following projects :"research on trinity teaching mode reform of animation practice course"[13JGY35], "research on model of local engineering university's art teaching brand" [12JGZ08] major which performing better on employment".[1], said the dean of admissions at Shanghai university, according to municipal education commission files. Employment, mandatory quota of college talent cultivation evaluation determines the future of professional education, it's clearly pointed out from the "Regarding the 2012 national ordinary higher school graduates employment notice" issued by the ministry of education, "seeking to establish the annual report system of employment of university graduates and key industries talent supply and demand, perfect professional dynamic adjustment and warning or exit mechanism, lower enrollment plan until stop for those majors which employment rates less than $60 \%$ for two consecutive years".[2]

There's problem for animation majors employment, but the reality is not the less demand of animation industry led to professional employment downturn, actually, cultural creative industry as a sunrise industry, the market demand for animation talent is obviously strong. The present employment of local colleges and universities crisis is not a reflection of culture industry withered flourish, but due to itself, such as blindly copy the established animation but lacking of corresponding hardware and software resources, education quality cannot meet the requirements, so it is impossible to training personnel in line with market demand. On the other hand, without the suited hardware and software resources, they can only set up lessons freely, apportionment courses compulsively, which also impossible to cultivate high quality students, it can be seen in most of local colleges.

We have to notice that the development of cultural industry should conform to the market rule; the professional education providing talents for culture industry also must conform to it. Lacking education quality which consisted by teaching goal, the pattern, and the conditions will worsen student employment situation, bring a chain reaction reducing constantly and gradually the enrollment students, eventually lead to insufficient enrollment and majors facing elimination. "Insufficient enrollment phenomenon will be more and more normal" in animation major in local colleges, but "insufficient enrollment doesn't mean totally none but generally decreasing, but it still can meet the need of college enrollment. Some schools find it's hard to recruit students, it shows that the examinee require more and more, students and parents' choices are tend to be more 
rational, thus, the it puts forward new requirements to the school: it' not enough to just open courses but to satisfy students and parents, also it's better to own characteristics, only by that can attract more people". Thus, for the animation major, "can't find their positioning could be fundamental problem."[3]

In addition, for those colleges and universities which added animation major should also notice that with the higher education marketization, labour market increases certain kind of talent will lead to corresponding professional demand which popular related majors. Under the promising employment situation, adding that major can bring benefits to school, such as attracting high quality students, expanding the scale of school, improve school tuition fees income and the graduates employment rate, etc. Animation major [1] has been developed rapidly under the premise of vigorously carry forward and support the cultural industry by the country, it aims to service for the cultural industry development. Despite there's strong demand for animation talent in cultural industry currently, but as the industry become more mature and saturated, the total demand is always limited. So, in the long run, the establishment, existence and development of most local colleges' animation major are also facing opportunity and challenge, market evolution. Various universities animation major, in other words, if cannot form its own brand and brand advantage in a short time, they will also face selection based on the market.

\section{PROFESSIONAL EDUCATION HOMOGENEITY LEADS TO DIFFICULT FORMATION OF PROFESSIONAL BRAND}

Basically consistent with the artistic designing major, animation developed from a small number of colleges and universities established major to one of the most "popular" majors in a short period of time. On the one hand, due to the country policy support and media publicity to animation industry has guided the career planning of tens of thousands of students, laid the students basis for animation major establishment and expansion of colleges and universities. To those examinee who choose animation major is looking for better jobs and better prospects of development, "for colleges and universities, set up the course is mainly because of the profit-driven and blind pursuit of complete professional disciplines".[4] Another prerequisite for this is "under the condition of market economy, on the majors set up and adjust, colleges and universities have more liberty, and the desire of pursuing interests is stronger than planned economy period. It provides motivation and possibility for colleges and universities to establish popular majors".[4]

However, animation major is a specialized category with high comprehensiveness and involves many disciplines. Also, it has higher requirements of learners' modeling and technology control ability than other majors do. So the difficulty of attending animation major and obtaining employment,compared to art design major, is far more superior. What's more, animation major teaching requires more investment in specialized hardware devices, but the colleges would not invest vigorously in the animation major because it's just a supporting role that makes profit only through tuition among all the majors, which leads to the situation that most of the local colleges' investment in software and hardware devices mismatches the number of major expansion. As a result, some of the colleges reach an agreement that they set courses for each individuals, avoid the equipment condition and set apportionment courses hardlyand-fast,which has been an unspoken rule after their "comprehensive mutual researches" , resulting in the exact echo of course systems and teaching contents of animation major in most of the colleges. It's not possible to cultivate high-level students, and causes many colleges to lose their own shooling characteristics because they fail to draw up unique training plans based on their own region and culture conditions, leading to a phenomenon that students of many colleges are cultivated "out of the same mould".

Actually, in those years from our nation putting up the cultural creative industry ideas, making cultural industry blueprints to supporting industry development, it's plain for us to see that the whole chains of animation industries involve various disciplines in fact. However, due to the lack of due software and hardware conditions, schooling history, the cognition of professional education and the industry chains as well as professional level of decision makers, the current talents cultivation plans and course setting of most colleges are confined either to 2D and 3D software technology levels such as simple flash and $3 \mathrm{dmax}$,or simple graphic design and animation basic contents, giving rise to the stereotyped phenomenon among all the colleges. As to the scenario planning, related products development, virtual reality and post-production of films, the colleges barely set foot in. Plus the blind imitation of teaching mode of old brand colleges, tiny fund investment and the experiences and qualification limits of professional teachers, those colleges' animation majors tend to be homogeneous in software and hardware conditions and schooling ideas and so on, which makes it difficult for them to establish their own brand and brand advantages.

\section{To Establish DifFERENT Diverse Specialized BRAND FOR DIFFERENT OCCUPATIONAL DIRECTION IN INDUSTRIAL SEGMENTATION}

Animation is a broad concept, for which "the State Ministry of Education" put forwards a "Big Animation" concept", "Animations are not only cartoons. Its application fields should include film packaging, film special effects, film ads, multi-media interactive animations, webpage animations,construction roaming animations and game animations". All the application fields of these "animations" are almost commercial, but they don't really contain scripts, plots, characters and scenes, and all take some products as a center, think and create the animations around those products in order to accomplish the goal to advertise these products". This is applied animation. Thus it can be seen, local colleges' animation majors can absolutely accomplish the diverse cultivation of animation majors talents based on their school characteristics and employment differentiation, so that they're able to improve the professional competence in the talents diverse cultivation and establish diverse competitive brands.

The employment situation of animation majors have been shown red card frequently these years, largely because the 
professional education of the local colleges have not properly oriented the professional talents cultivation on the condition that they analyze their own advantages and disadvantages rationally, and they follow those colleges who are mature in animation major development blindly in the aspects of teaching mode and course setting. Due to the mismatch of education resources with old brand colleges, the united condition based on pure animation production teaching in talents cultivation of local colleges' animation majors severely weakens their own competitive ability. "Currently the teaching goals of animation majors of all the colleges in our country are almost the same, namely to let the students finish an animation independently. This teaching goal is mainly from Beijing Film Academy. ", "But the teachers neglect one point that their colleges are completely different from BFA. BFA has a long film history and a lot of experts in filmology. But design colleges do not have the ability. It's far from being enough if only to repeat what the book says with one or two textbooks in hands."

However, the colleges with post construction animation majors are not really advantageous at all. On the contrary, due to the bedding of region and interdisciplines such as computer and industry design, they usually have their own unique advantages in the animation industry fields. For instance, colleges experienced in traditional modeling majors have the connate advantages in original animation and cartoon fields. To seek a diverse talents cultivation mode is the necessary choice for talents cultivation of local animation majors. Only if effectively avoiding the competitive pressure with old brand animation majors, can these colleges "carry out a targeted diverse cultivation combined with schooling characteristics of local colleges in order to improve the students' employability"

The most important reason of animation majors getting stuck in the employment bottleneck after only a few years is that the requirements of animation's modeling skills is far more than art design's, which also accounts for the reason why it's harder to get into the animation majors than art design majors. Those colleges lacking modeling professional training tradition bedding in animation majors cause most of the students fail to cultivate superior original animation creative ability. One of the reasons relies on the teaching inexperience and lack of faculty, the other is that the widespread decline of art examinees' source modeling ability and the lower of recruit threshold as well as the few students with good modeling skills would not like to study in general colleges. The lack of high quality students enrollment causes these colleges hardly to cultivate preferable animation specialized talents in modeling. Thus, those colleges who have deep accumulation in traditional modeling majors can utilize this advantage, and intensify animation characters creation, scene setup, original animation portray in the earlier and medium-term stage teaching in animation majors talents cultivation plans.

Similarly, those colleges with profound accumulation in literature education can integrate the curriculum modules of play writing, to enhance the early educational research of animation industry; Those colleges with the advantage of computer software education can take usage of software development to enhance the research of animation software, plug-in module, expression and mobile games of students, consequently to enhance their operability of software special effects, give support to the animation expression effect of the middle and later periods, and simultaneously make up for the deficiencies of lacking freehand sketching capacity; Those colleges with obvious advantage of industrial design education can enhance the education in the aspects of animation major props, peripherals and so on.

If the animation major of colleges can be reasonably located on the basis of combing own actual situation and having a thorough grasp of segmentation modules of animation industry chain, for themselves, they can draw on each other's strength, and for the whole animation industry chain, the major education refers to variety of knowledge and depth related to animation industry, and simultaneously can provide major talents up to different types of positions. Such actions not only keep off the competitive pressures from those master animation majors, but also cater to the whole requirements to personnel types in the animation industry chain, and simultaneously get explicit self-characteristics and development direction to proceed necessary source and experience accumulation for the establishment of major brand. Only this can help to keep expanding their own popularity to attract excellent students source persistently, get them cultivated well, and make the virtuous cycles of effective employment of high quality for the graduates, which can finally achieve the healthy development of animation major differentiation education, to build their own society brand.

\section{ENLIGHTENMENT OF BRAND ESTABLISHMENT TO ANIMATION MAJOR IN LOCAL COLLEGES FROM MICRO- ANIMATION}

There seems to be no relationship between the two concepts, micro-animation movies and animation major. But propagation mode, production modality and contents, all provide something to be learned for the development and brand establishment of animation major in local colleges.

The arrival of new media time, especially movie and television products have new transmission route. Micro film refers to subminiature film, which means "those videos specialized in those played in all kinds of new media platforms, fit for being watching in moving state and shorttime leisure state, possessing the support of complete schemes and systematic production system with complete story line, and possessing the features of 'being showed in micro-time, being made in micro-cycle and being invested in micro-scale'. Its contents combine those themes of humor and funny, fashion and trend, public education and commercial custom, which can become entirety separately, or in series. "Micro film is born in this fashion trend.

In the aspect of form, "being showed in micro-time, being made in micro-cycle and being invested in micro-scale" of micro animation film have solved the problems of insufficient hardware and capital for local universities, and provided propaganda channel for brand establishment of animation majors in colleges. The reality of micro animation films prove that those successful animation movies don't lie in the time duration, but the expression of concept and technology. The 
creator can play the beating thought with dynamic story line. The animation majors of local colleges can take the creation of micro animation movie as the moment, to enhance the major practical link of students and improve the ability of movie creation and technical control of majors. And under the circumstance of lesser investment or even zero-investment, the more comprehensive animation works can be formed to realize the effective butt joint of major teaching and market. At the same time, these works can be broadcast through multimedia and multi-channel for free. For a major, the formation of mature animation works is not only the achievements in scientific research of teaching, to provide practical opportunities for major teaching, but also can transfer the achievements in scientific research of teaching to actual propaganda capitals, to raise the recognition of majors. As this avoids the deficiency in the competition with those old colleges making voluminous animations of complete movie theatre, the brand establishment of those animation majors in local colleges becomes possible.

In the aspect of contents, micro animation films "combine those themes of humor and funny, fashion and trend, public education and commercial custom, which can become entirety separately, or in series. "What's most important is that "the concept of micro animations determines that their audiences are not children at all, but those social mainstream groups with a higher cultural level, sensitivity to all kinds of current affairs and information, enthusiasm about mobile phone internet and other IT culture and modern lifestyle". As the micro animation films break down the barriers of producing capitals and transmission channels, and have wider dimensionality in those aspects of content, producing method and manifestation pattern, which greatly expands the teaching contents of animation major practice in local colleges, and lays the actual foundation of adjusting specialty structure. There is no need for the animation majors of local colleges holding the grudge of the hardship of movie theatre animation courses, while they can look for breakthroughs in those non movie theatre animation teachings fit for themselves, to realize the significant development in the establishment of major brand and themselves.

\section{CONCLUSION}

As the animation major is a new major in many local colleges, competitiveness of their teachers' condition and other are relatively weaker than that of those old animation majors. And when being established, they aimlessly refer to the curriculum provision and teaching pattern of those animation majors in old colleges, which cannot help to develop their own brand value and those students cultivated have no competitiveness at all. Therefore, they should start from the subdivision of animation industry, grasp their own precedence of sources, avoid the blind simulation from old colleges, establish the pattern and objective of cultivating talents fit for themselves on a basis of strengthening the differences, then they only can achieve the brand development of major education management, and finally can promote their competitiveness of this major.

\section{REFERENCES}

[1] http://news.qq.com/a/20120204/000207.htm?pgv ref=aio2012\&ptlang= 2052

[2] http://www.qdqss.cn/2011/november/8E80E062.html

[3] http://edu.ifeng.com/gundong/detail_2011_08/19/8519937_0.shtml

[4] DENG Yue-min,The research and analysis of convergence problem of major setting in colleges of our country[J], Journal of Guangdong University of Technology(Social Sciences Edition),2009,(2):4-8.

[5] WangWei, The new ideas of animation major development in design colleges[J], Journal of Changchun University of Science and Technology,2011,(09):23-24.

[6] ZhuLiPing,WeiXiangMing.The research and analysis of talent differentiation cultivation pattern of business administration major in local colleges[J],Education Teaching Forum,2010,(27):217-218

[7] http://baike.baidu.com/view/6180260.htm?wtp=tt 